\title{
Geomorphic effects of gravel augmentation on the Old Rhine River downstream from the Kembs dam (France, Germany)
}

\author{
Valentin Chardon ${ }^{1,2, *}$, Laurent Schmitt $^{1}$, Hervé Piégay ${ }^{2}$, Fanny Arnaud $^{2}$, Jordane Serouilou ${ }^{1}$, \\ Jérôme Houssier ${ }^{1}$, and Anne Clutier ${ }^{3}$ \\ ${ }^{1}$ University of Strasbourg, LIVE - UMR 7362 CNRS/ENGEES - LTER - "Zone Atelier \\ Environnementale Urbaine", 67083 Strasbourg Cedex, France \\ ${ }^{2}$ University of Lyon, EVS - UMR 5600 CNRS, 69362 Lyon Cedex, France \\ ${ }^{3}$ Électricité de France, Centre d'Ingénierie Hydraulique (CIH) - 73370 Le Bourget-du-Lac Cedex, \\ France
}

\begin{abstract}
During the last 30 years, river restoration activities aiming to improve the functionality of degraded fluvial ecosystems increased markedly. For large rivers, it remains difficult to evaluate restoration efficiency and sustainability due to the lack of standardized monitoring metrics. From 2010 to 2016, three gravel augmentations were performed on the Old Rhine, a by-passed reach downstream from the Kembs dam (FranceGermany). A geomorphic monitoring combining topo-bathymetric surveys, bedload tracking and hydraulic modelling allows to evaluate the successfulness of these actions. Results show that, to be mobilized, artificial sediment deposit should be located in concavity rather than convexity areas, due to higher shear stresses for moderate floods $\left(\mathrm{Q}_{2}\right)$. Sediment starvation appeared rapidly on the restored reaches once the sediment wave moved downstream, as a consequence of limited upstream sediment supply. Bathymetric homogenization was observed along and downstream from the restored reaches without creation of new fluvial forms. This research highlights that future actions should include channel enlargement downstream of gravel augmentations, which would promote sediment deposition and habitat diversification. Sediments excavated during artificial widening could be stored and injected progressively into the upstream part of the Old Rhine to benefit the downstream sections.
\end{abstract}

\section{Introduction}

Many large rivers have been impacted by engineering works designed for flood control, navigation, agriculture development and hydro-power production. These facilities modified flow regime and sediment flux inducing severe habitat simplifications and biological alterations [1]. During the last three decades, a growing number of restoration actions were promoted to balance these alterations and recover fluvial processes and associated ecosystem services [2]. Gravel augmentation is increasingly practiced to regain morpho-sedimentary

\footnotetext{
* Corresponding author: valentin.chardon@live-cnrs.unistra.fr
} 
dynamics and enhance alluvial biodiversity downstream from dams, where river reaches are often paved and fixed. However, this kind of restoration is expensive and feedbacks are still rare regarding its efficiency and sustainability [3].

This contribution aims to provide feedback on three gravel augmentations achieved since 2010 on the Old Rhine River downstream from the Kembs dam. Our objectives are: (i) to characterize the best hydraulic settings to mobilize artificial sediment deposit, (ii) to assess gravel transport processes through hydrological events, and (iii) to measure geomorphic responses induced by gravel augmentations. We further put forward management recommendations to optimize future benefits from this type of restoration.

\section{Study area}

The Old Rhine, from the Kembs diversion dam to Neuf-Brisach, is a $50 \mathrm{~km}$-long reach by-passed by the "Grand Canal d'Alsace", which encompasses four hydroelectric power plants (Fig. 1). Its ecological state is affected by severe geomorphic alterations (e.g. channel bed stabilization, narrowing, bed degradation and armoring) induced by engineering works since the $19^{\text {th }}$ century [4]. Since 2010, three gravel augmentations were performed in the upstream part of the Old Rhine (Interreg, Kembs I1, Kembs I2; Fig. 1). The Interreg artificial deposit was placed in a concavity area whereas Kembs I1 and Kembs I 2 were set in a convexity area. The $D_{50}$ of injected sediments ranges from 12 to $112 \mathrm{~mm}$ and volumes for each injection (about $20.000 \mathrm{~m}^{3}$ ) are close to the estimated annual bedload transport capacity of the reach [5].

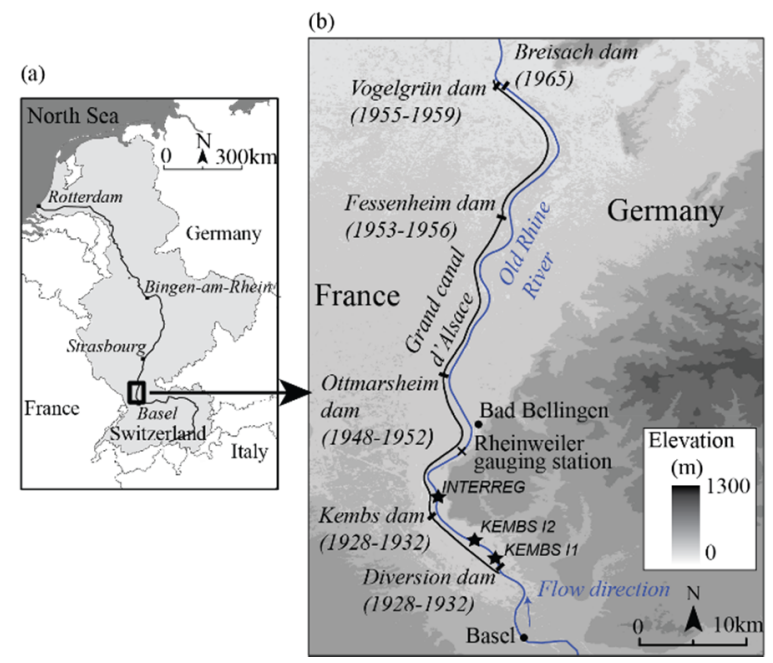

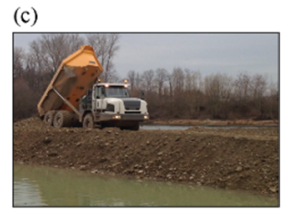

(d)
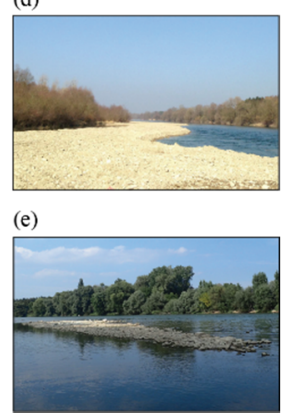

Fig. 1. (a) Location of the by-passed study reach in the River Rhine Basin, (b) location of gravel augmentations, (c) Kembs I2 gravel augmentation in progress, (d) Kembs I2 artificial sediment deposit and (e) residual artificial sediment deposit of Kembs I2 gravel augmentation after a $\mathrm{Q}_{4}$ flood.

\section{Methods}

The monitoring framework is based on a before-after restoration scheme. Three to seven monitoring campaigns were performed for each gravel augmentation (Fig. 2). 


\subsection{Geomorphic monitoring}

For each monitoring period (Pi; Fig. 2), a topo-bathymetric survey was conducted along and downstream from gravel augmentation sites to quantify morphological evolutions. Data collection for the Interreg site is detailed in [6]. For Kembs I1 and Kembs I2 sites, initial states (S0, Fig. 2) were defined on cross-section profiles spaced at 5 to $50 \mathrm{~m}$ intervals in February 2015 and November 2015, respectively. Since March 2016, an annual topobathymetric survey was performed by airborne LiDAR.

For each site, about 1500 particles equipped with radio-frequency tracers (PIT tags) were deployed on each artificial sediment deposit. The grain size distribution of tracers is close to the natural surface grain size distribution of emerged bars along the study reach for Kembs I1 and Kembs I 2 sites. For Interreg site, the grain size of tracers was approximately equidistributed between the three major classes (45.3-64 mm, 64-90.5 mm and 90.5-128 mm), less than $8 \%$ and $1 \%$ for grain size equal to $32-45.3 \mathrm{~mm}$ and $128-181 \mathrm{~mm}$, respectively. During each survey, tracers were tracked with a detection antenna connected to a reader system and located by GPS (planimetric accuracy $=0.1 \mathrm{~m}$ ).

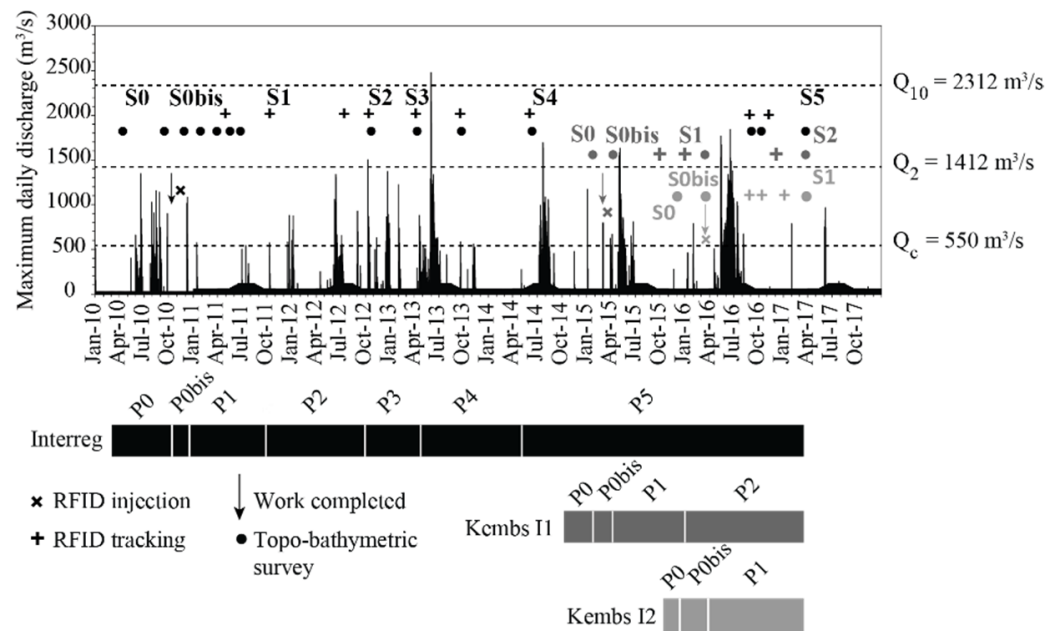

Fig. 2. Temporal monitoring framework vs. maximum daily discharges in the Old Rhine. Si represents each survey and Pi the time period between two surveys.

\subsection{Hydraulic modelling}

We used a 2D hydraulic model in unsteady flow simulation to simulate hydraulic conditions of peak flows during period 1 on each artificial sediment deposit area to compare them with erosion dynamics. The modelling was performed with the HEC-RAS v.5.0.3 software between the Kembs diversion dam and the Rheinweiler gauging station (Fig. 1). We used the 2017 LiDAR and topo-bathymetric surveys made during S0bis (Fig. 2). Water levels and instantaneous discharges measured at the Rheinweiler gauging station (time step = $15 \mathrm{~min}$ ) were used as downstream and upstream boundaries conditions, respectively. The applied Manning's coefficients are those calculated by [7]. The hydraulic metrics were extracted at each cell $(0.5 \mathrm{~m})$ of the Digital Elevation Model. 


\subsection{Data analysis}

To relate morphological changes of artificial sediment deposit to hydraulic conditions, we calculated the dimensionless bed shear stress for each peak flow during the monitoring period P1 as follows:

$$
\tau^{*}=\frac{\tau_{0}}{\left(\rho_{s}-\rho_{w}\right) * g * D_{50}}
$$

where $\tau_{0}=\rho_{w} g h S\left(\mathrm{~N} \cdot \mathrm{m}^{-2}\right), \rho_{s}$ is the sediment density $\left(\mathrm{kg} \cdot \mathrm{m}^{-3}\right), \rho_{w}$ the water density $\left(\mathrm{kg} . \mathrm{m}^{-}\right.$ $\left.{ }^{3}\right), g$ the acceleration due to gravity $\left(\mathrm{m} . \mathrm{s}^{-2}\right), h$ the water depth $(\mathrm{m}), S$ the local energy slope $\left(\mathrm{m} . \mathrm{m}^{-1}\right)$ and $D_{50}$ the median grain size of each gravel augmentation determined by volumetric sampling. We calculated maximum shear stresses on cross-section spaced to 25 to $50 \mathrm{~m}$ and mean shear stress on each artificial sediment deposit.

To assess tracer travel distances for each period, we estimated tracer cloud centroid positions [6]. This metric is based on the assumption that recovered tracers are representative of all tracers [8]. The tracer cloud centroid position $\left(\mathrm{m}, C P_{S i}\right)$ is defined as:

$$
C P_{S i}=\frac{\sum_{i=1}^{n} L P_{\left(x_{i}\right)}}{n}
$$

where $L P_{(x i)}$ is the longitudinal position of the tracer $(\mathrm{m})$ along the active channel centerline and $\mathrm{n}$ is the number of tracer recovery. Tracers whose grain ranges between 22.6 and $32 \mathrm{~mm}$, which were injected for Kembs I1 and Kembs I2 sites and not for the Interreg site, were excluded from the dataset to allow comparison between the three sites.

The virtual velocity metric $\left(\mathrm{m} \cdot \mathrm{h}^{-1}\right)$ was calculated by integrating the duration of bedload transport for each flood exceeding the critical discharge [9]. We modified the calculation by replacing the mean distance of all moved particles by the travel distance of the tracer cloud centroid between two surveys:

$$
V_{P_{(i)}}=\frac{C P_{S i+1}-C P_{S i}}{t>Q_{c}}
$$

where $Q_{c}$ is the critical discharge $\left(\mathrm{m}^{3} \cdot \mathrm{s}^{-1}\right)$, $\mathrm{t}$ is time exceeding critical discharge $\left(\mathrm{h}^{-1}\right)$

In order to study how the flow competence drives bedload mobility, we calculated the cumulative excess stream energy [10] $\left(\mathrm{J}^{\mathrm{m}} \mathrm{m}^{-2}\right)$ for each period as follow:

$$
\sum_{i=1}^{\mathrm{n}}\left(\omega_{(t)}-\omega_{c}\right)=\sum_{i=1}^{n} \frac{\rho_{w} g\left(Q_{\mathrm{t}}-Q_{c}\right) S}{W} * 600
$$

where $Q_{t}$ is the instantaneous discharge $\left(\mathrm{m}^{3} \cdot \mathrm{s}^{-1}\right), Q_{c}$ is the critical discharge $\left(\mathrm{m}^{3} . \mathrm{s}^{-1}\right), S$ is the average local bed slope $\left(\mathrm{m} . \mathrm{m}^{-1}\right), W$ is the mean active channel width $(\mathrm{m})$, and $\mathrm{n}$ is the number of interval time where $Q_{\mathrm{t}}>Q_{c}$. As the time-step measurements at the Basel gauging station equal $10 \mathrm{~min}$, we multiplied the excess stream energy by $600 \mathrm{~s}$ to calculate the cumulative excess stream energy between two measures of discharge.

To estimate the cross-sectional morphological diversity, we used the Cross-Section Diversity (CSD) index which is calculated as follows [11]: 


$$
C S D=\frac{\sum_{i=1}^{n}\left|\Delta Y_{i}\right|}{\sum_{i=1}^{n-1} X_{i}}
$$

where $\Delta Y_{i}$ is the height difference between two consecutive points along the cross-section (m) and $X_{i}$ the distance between them (m).

\section{Results and discussion}

\subsection{Best conditions to mobilize artificial sediment deposit}

We observed an increase in maximum vertical erosion of artificial sediment deposit as $\tau^{*}$ increased (Fig. 3.a). Because of complex hydraulic conditions of each site and the occurrence of different erosion processes, there is a local variability in channel responses. A logarithmic relationship was also identified between eroded volumes of artificial sediment deposit and the mean $\tau^{*}$ value (Fig. 3.b). For a similar range of floods, shear stresses were logically higher in concavity than in convexity areas. Thus, artificial sediment deposits must be deployed in concavity zones to promote their erosion from moderate flood.

(a)

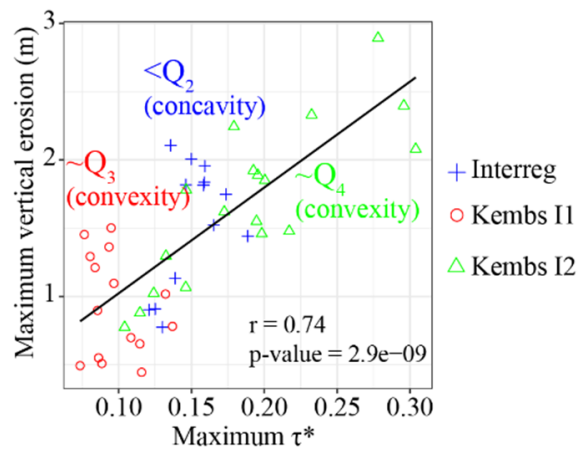

(b)

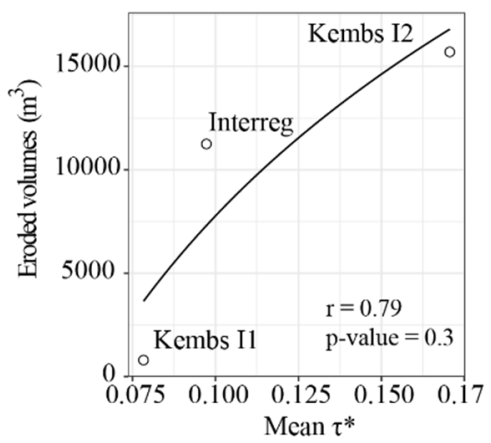

Fig. 3. Relations between (a) maximum vertical erosion and dimensionless peak flow shear stress calculated on each cross-section (flood intensity and gravel augmentation locations are indicated), and (b) eroded volumes and mean dimensionless peak flow shear stress for each artificial sediment deposit. Studied peak flows are those observed during the first flood events following the gravel augmentations (P1; see Fig. 2).

\subsection{Bedload transport processes from tracer surveys}

The longitudinal position of tracers through time is plotted on Fig. 4. The first two tracking surveys for the Interreg deposit suggest sediment transport by translation (Fig. 4.a). From surveys 3 to 5 , the tracer cloud dispersion increased. Survey 5 shows that bedforms control sediment deposition when the dispersion is advanced, a process that corresponds to bedload diffusion transport. Indeed, tracer clusters were preferentially observed at riffle heads (Fig. 4.a-c). For Kembs I1 and Kembs I2, the longitudinal distribution of tracers is heavy-tailed because some tracers were still trapped on the residual artificial sediment deposit whereas others travelled downstream (Fig. 4.b). At the moment for these sites no clear pattern transport in relation with bedforms was revealed (Fig. 4.d). Fig. 5 shows that virtual velocity 
was inversely correlated to cumulative excess stream energy. A decreasing in virtual velocity was concomitant with an increase in cumulative excess stream energy. This can be interpreted as progressive tracer burying. For Interreg P4, the observed high virtual velocity is close to that for P1, and can be explained by a high peak flood $\left(\sim \mathrm{Q}_{15}\right)$.

For the same range of cumulative excess stream energy, virtual velocities calculated for Kembs I1 and Kembs I2 are lower than the ones observed for Interreg (Fig. 5). These reduced transport distances can be explained by an initial coarser armour layer at the most upstream sites, with a stronger gravel trapping capacity [12].

Tracer cloud centroid positions are plotted for each grain size classes on Fig. 4.a.b. For Interreg, a relationship between the travel distance of tracer cloud centroids and grain size appeared during P4, and was clearly intensified during P5 (Fig. 4.a). This relation was also observed for Kembs I1 during P2 (Fig. 4.b). We explain these results by the fact that full mobility was progressively replaced by partial mobility, because diffusion process has progressed. This change is more or less rapid depending on mobilized sediment volumes and suggests the re-establishment of the initial armour layer [8] due to the limited upstream sediment supply.

(a)
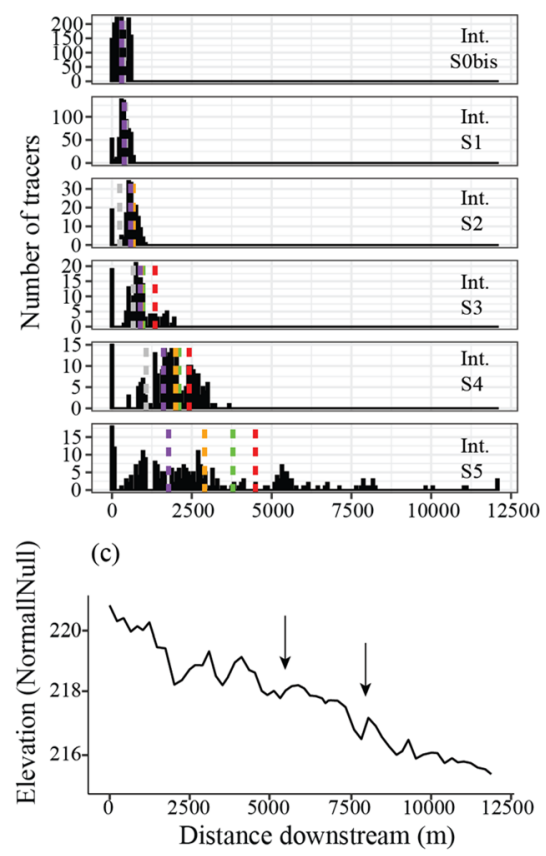

(b)

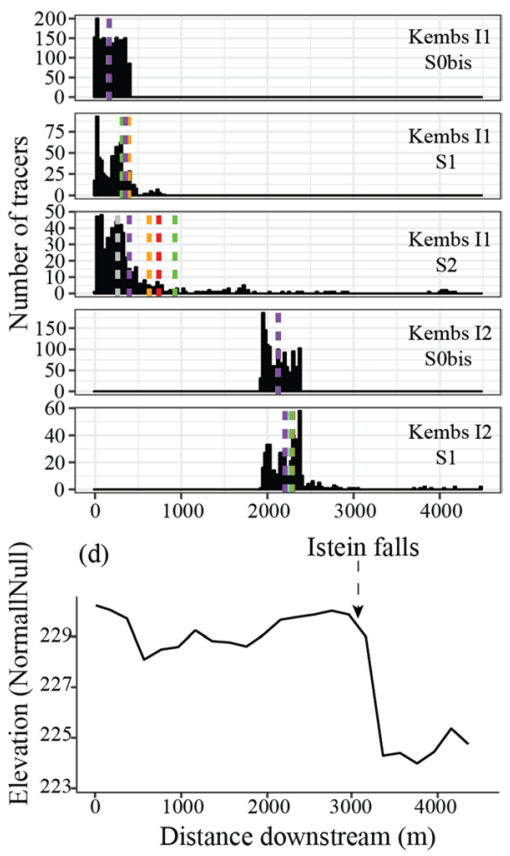

Fig. 4. Longitudinal position of detected tracers (a) following Interreg gravel augmentation (Int.), (b) following Kembs I1 and Kembs I2 gravel augmentations. Thalweg elevation along and downstream (c) Interreg gravel augmentation and (d) Kembs I1 and Kembs I2 gravel augmentations. Red, green, orange, purple and grey dashed lines indicate tracer cloud centroids for grain sizes equal to 32-45.3 $\mathrm{mm}, 45.3-64 \mathrm{~mm}, 64-90.5 \mathrm{~mm}, 90.5-128 \mathrm{~mm}$ and $128-181 \mathrm{~mm}$, respectively. Interreg tracers located in the first 12 meters of gravel augmentation and Kembs I1 tracers trapped on the residual artificial sediment deposit were excluded for centroids calculation. The black arrows indicate the tracer clusters recovered during S5. 


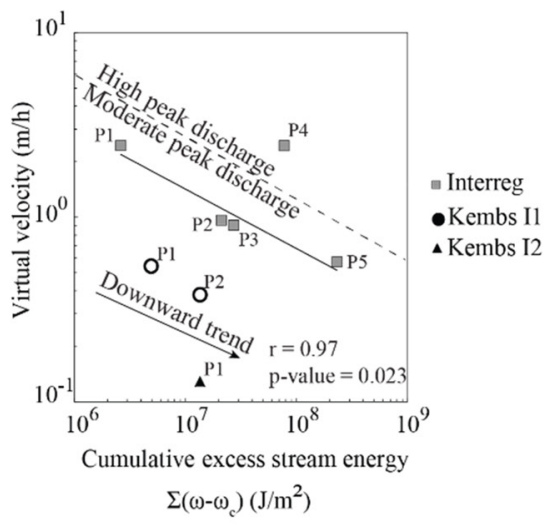

Fig. 5. Virtual velocity of tracer cloud centroids according to cumulative excess stream energy. The empirical law is based on Interreg survey results excluding P4.

\subsection{Bedform responses}

Fig. 6 shows the cumulative cross-section diversity index in a downstream direction for each survey compared to the initial state $(\mathrm{S} 0-\mathrm{Si})$. The cumulative index is negative from $\mathrm{S} 0$ to $\mathrm{S} 1$ along and downstream each gravel augmentation. Positive values were solely observed locally on the Interreg site from S0 to S5 and explained by the formation of a median bar, which was only partly related to the gravel augmentation. This result suggests that gravel augmentations caused channel homogenization during the downstream propagation of the sediment wave. The slope diminution of the CSD curve through time (Interreg site) suggests that these effects are temporary.

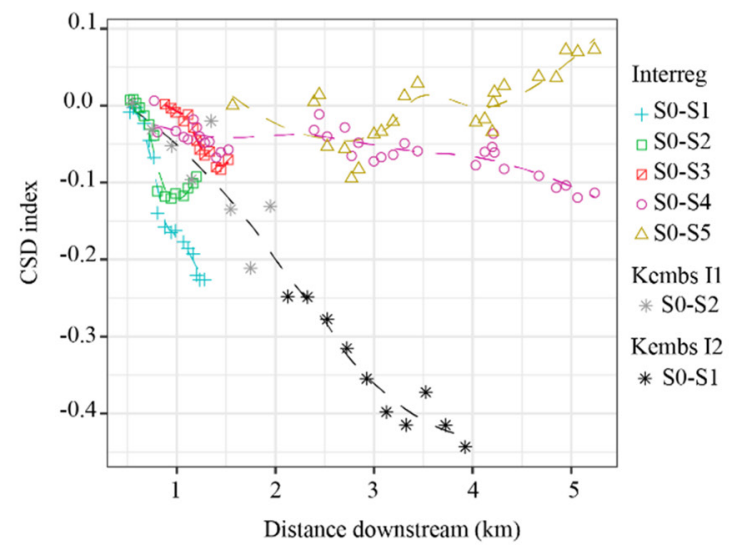

Fig. 6. Cumulative cross-section diversity (CSD) index from S0 to S5 surveys for the Interreg gravel augmentation, S0 to S2 for Kembs I1 and S0 to S1 for Kembs I2 gravel augmentations.

\section{Conclusion}

This paper provides feedback on three gravel augmentations conducted on the Rhine downstream from the Kembs dam through geomorphic monitoring and hydraulic modelling. We assessed the best hydraulic settings for mobilizing artificial sediment deposit during moderate floods $\left(\mathrm{Q}_{2}\right)$. These conditions correspond to concavity rather than convexity areas, where shear stresses are higher. Tracer surveys showed that sediments spread downstream 
rapidly (two to four hydrological events) and sediment starvation is re-established if no more gravel augmentations are done. Moreover, the cross-section diversity index indicated that gravel augmentations did not significantly diversify aquatic meso-habitats.

This research highlights that the currently performed restoration measures are insufficient and should be completed by channel widening a few kilometres downstream gravel augmentations to reduce shear stress, promote sediment deposition and create new geomorphic units (e.g. bars, secondary channels...). These deposits could promote progressive bank erosion, inducing bedload supply into the channel. Furthermore, new hydraulic conditions may induce the vegetalization of sediment deposits which could slow down sediment transfer. These positive retroactions could improve the sustainability of restoration actions. Sediments excavated during artificial channel widening could be stored temporarily and injected progressively into the upstream part of the Old Rhine [13].

Financial support: project 'Redynamization of the Old Rhine 2009-2012' (FEDER Interreg IV Upper Rhine), Région Grand Est (2016-2017, 328/14/C1 2016-2017), Electricité de France (EDF) within several research collaborations (2009-2012, EDF 5500-AAH-5910047888; 2013-2014, EDF 55004300937910; 2014-2018, EDF 5910132058). We thank Claire Rambeau for language proofreading. We also thank the two anonymous reviewers whose constructive remarks helped improve the manuscript.

\section{References}

1. G.M. Kondolf, S.Anderson, R.Lave, L.Pagano, A. Merenlender, E.S. Bernhardt, Restor. Ecol. 15, pp. 516-523 (2007)

2. E. Buisson, R. Jaunatre, B. Regnery, M. Lucas, J.-F. Alignan, A. Heckenroth, I. Muller, I. Bernez, I. Combroux, S. Moussard, T. Glasser, S. Jund, S. Lelièvre, S. Malaval, M.-P. Vécrin-Stablo, S. Gallet, Restor. Ecol. 26, pp. 36-44 (2017)

3. C. Staentzel, F. Arnaud, I. Combroux, L. Schmitt, M. Trémolières, C. Grac, H. Piégay, A. Barillier, V. Chardon, J.-N. Beisel, River Res. Appl. 34, pp. 153-164 (2018)

4. F. Arnaud, Thesis, 280p. (2012)

5. K. El kadi Abderrezzak, Report H-P73-2009-00402-FR, pp. 28-39 (2009)

6. F. Arnaud, H. Piégay, D. Béal, P. Collery, L. Vaudor, A.-J. Rollet, Earth Surf. Process. Landf. 42, pp. 2147-2166, (2017)

7. C. Béraud., Thesis, 277p. (2012)

8. H. Piégay, F. Arnaud, M. Cassel, T. Depret, A. Alber, K. Michel, A.-J. Rollet, L. Vaudor, BSGLg 67, pp.77-91 (2016).

9. M. A. Hassan, M. Church, P. J. Ashworth, Earth Surf. Process. Landf. 17, pp. 617-627 (1992)

10. J. M. Schneider, J. M. Turowski, D. Rickenmann, R. Hegglin, S. Arrigo, L. Mao, J. W. Kirchner, J. Geophys. Res. Earth Surf. 119, pp. 533-549 (2014)

11. W.Gostner, M.Alp, A.J. Schleiss, C.T Robinson. Hydrobio. 712, pp. 43-60 (2013)

12. K. Koll, K.Koll, A. Dittrich. River Flow, pp. 929-936 (2010)

13. V. Chardon, L. Schmitt, J. Serouilou, J. Houssier. Report DEA 10616, 49p. (2017) 